Snelleman, M., Schoenmakers, T.M., Mheen, D. van de. The relationship between perceived stress and cue sensitivity for alcohol. Addictive Behaviors: 2014, 39(12), 1884-1889

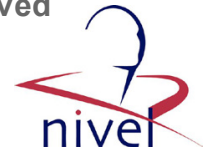

\begin{tabular}{|l|l|}
$\begin{array}{l}\text { Postprint } \\
\text { Version }\end{array}$ & 1.0 \\
\hline Journal website & http://linkinghub.elsevier.com/retrieve/pii/S0306-4603(14)00255-X \\
\hline Pubmed link & http://www.ncbi.nlm.nih.gov/pubmed/25133978 \\
\hline DOI & 10.1016/j.addbeh.2014.07.024
\end{tabular}

This is a NIVEL certified Post Print, more info at http://www.nivel.eu

\title{
The relationship between perceived stress and cue sensitivity for alcohol
}

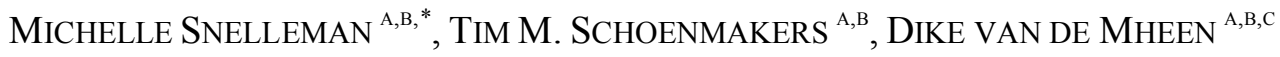 \\ a IVO Addiction Research Institute, Heemraadssingel 194, 3021 DM, Rotterdam, The \\ Netherlands \\ b Erasmus Medical Center Rotterdam, P.O. box 2040, 3000 CA, Rotterdam, The \\ Netherlands \\ c Department of Health Promotion, Maastricht University, P.O. box 616, 6200 MD \\ Maastricht, The Netherlands
}

\begin{abstract}
Previous research has shown that cue sensitivity and stress affect the risk for relapse in alcohol-dependent patients. Theoretically, a link between the two can be expected. However, a clear overview of the interplay of these factors is not yet available. The purpose of this review was to examine the empirical evidence for the influence of stress on sensitivity for alcohol-related cues.

Empirical studies indexed in PubMed, EMBASE, PsycINFO, and Web of Knowledge that assessed the relation between stress and sensitivity for alcoholrelated cues using subjective, behavioral and/or physiological measures were included in the review.

Of the 359 articles screened, 12 were included in the review. Nine articles supported the existence of the relationship between stress and heightened cue sensitivity for alcohol-related cues, whereas three articles did not support our hypothesis.

We conclude that the relationship between stress and sensitivity to alcohol cues appears to exist. In fact, there may be different factors at play: our review points toward (1) differences between the effect of psychological stress and physiological stress on cue-sensitivity, and (2) individual differences regarding coping drinking which may explain stress-induced cues sensitivity.
\end{abstract}

\section{INTRODUCTION}

Despite years of research and great progress in developing treatments for alcohol dependence, rates of alcohol relapse remain high (Boothby and Doering, 2005 and Finney et al., 1996). A number of theories regarding the reasons for relapse focus on the role of stress and sensitivity for alcohol-related cues or 'stimuli.' For example, according to the Affective Processing Model of Negative Reinforcement (Baker, Piper, McCarthy, Majeskie, \& Fiore, 2004), stressors cause or increase 
Snelleman, M., Schoenmakers, T.M., Mheen, D. van de. The relationship between perceived stress and cue sensitivity for alcohol. Addictive Behaviors: 2014, 39(12), 1884-1889

negative affect, which in turn activates the learned rewarding properties of alcohol (or other addictive substances) that relieve negative affect, thereby motivating the individual to use again.

Another factor contributing to increased risks of relapse is cue sensitivity. Hereby we mean that the brain is sensitive to alcohol-related cues, leading to a strong reaction toward these cues, i.e., cue reactivity. According to the Incentive Sensitization Theory (Robinson \& Berridge, 1993), specific cues (e.g., stimuli, situations) become associated with an addictive substance through repetitive use in the presence of these cues. The substance-related cues become attractive and therefore salient to the addict and activate a neurological hypersensitive reaction to a substance (Grüsser et al., 2004 and Tapert et al., 2003). This hypersensitivity may remain even after long periods of abstinence (Robinson \& Berridge, 2001, cf. Koob \& Le Moal, 2001). Combining the two aforementioned theories, we hypothesized that under stress, cues that have become associated with alcohol via previous experience become more salient, and the brain is more sensitive to these cues.

In experimental studies, stress has been induced by various types of stressors. Dickerson and Kemeny (2004) categorized acute psychological stressors into five types of stress induction procedures: performance of cognitive tasks; public speaking with verbal interaction; a combination of the aforementioned; noise exposure; and real (e.g., pictures, film) or mental (i.e., imagination, recall) exposure to emotioneliciting material or situations. All five types of stress induction evoke psychological distress, and public speaking combined with a cognitive task also evokes physiological stress.

There are a number of methods to assess cue sensitivity: physiological measures, subjective measures, behavioral measures, or a combination of these measures. Physiological measures that are most often used include heart rate or heart rate variability (HRV) and skin conductance (Carter and Tiffany, 1999, Cooney et al., 1997 and Waters et al., 2009).

Cue sensitivity may also be measured subjectively and is often defined as increases in craving or the desire for alcohol after encountering alcohol-related cues (e.g., Bohn et al., 1995 and Schulze and Jones, 2000). Finally, another indicator of cue sensitivity is attentional bias, i.e. a selective focus on alcohol-related cues.

Attentional bias is assessed with a reaction time task assessing the extent to which alcohol-related cues are selectively attended to as compared to neutral cues (Field \& Cox, 2008).

\section{MeTHODS}

A literature search was conducted using PubMed, EMBase/Medline, Web of Knowledge, and PsycINFO, covering all articles published until September 2013. We used the following key terms: alcohol* and ethanol*; cue*, trigger*, stimuli; stress*, ACTH, CRF, cortisol, HPA, and distress; reactivity, sensitivity, cognitive bias and implicit cognition. A total of 12 articles were selected (Fig. 1).

\section{[FIGURE 1]}

\section{RESULTS}

The number of identified eligible studies for this review was relatively small and study samples were diverse. Therefore, we opted for a descriptive synthesis of the 
Snelleman, M., Schoenmakers, T.M., Mheen, D. van de. The relationship between perceived stress and cue sensitivity for alcohol. Addictive Behaviors: 2014, 39(12), 1884-1889

results including a calculation of effect sizes. Characteristics of the 12 included articles are presented in Table 1.

\section{[TABLE 1]}

We found three global categories of studies based on their design. Studies in category one used experimental within-subjects designs. These designs are the best test of causal relationships and therefore provide the strongest evidence. The second strongest category includes experimental studies using between-subjects designs. These studies are considered to provide somewhat weaker evidence than category one, because participants are exposed to only one mood induction condition. The third category with the weakest evidence includes correlational studies from which no causal inferences can be made.

\subsection{Category 1}

In the first category $(\mathrm{N}=5)$, participants were exposed to both a stress and a neutral mood induction. Stress was induced by either using imagery (exposure to emotioneliciting material) or performing a high-speed task (cognitive task). Cues were presented in vivo by the sight and/or smell of the preferred beverage (Coffey et al., 2006, Jansma et al., 2000, Nosen et al., 2012, Pratt and Davidson, 2009 and Ray, 2011).

Coffey et al. (2006) found that participants reported greater craving after trauma imagery followed by an alcohol cue than after trauma imagery followed by a water cue, or after neutral imagery followed by either an alcohol cue or a water cue. These results indicate that trauma-induced stress and exposure to alcohol cues increases craving as compared to neutral mood states and alcohol cues.

Similar results were obtained in another study (Nosen et al., 2012). The greatest increases in craving and salivary flow were observed after trauma imagery was followed by an alcohol cue and these increases were larger than after neutral mood induction and alcohol cue exposure. Both studies support our hypothesis.

Jansma et al. (2000) found that in all conditions (mood induction: distressed, depressed, and neutral), heart rate was lower, and heart rate variability, blood pressure and self-reported desire to drink were higher during alcohol cue exposure than during each mood induction; this hints toward an overall alcohol cue sensitivity.1 However, there were no differences in alcohol cue sensitivity measures between conditions. Therefore, this study does not support our hypothesis: the changes induced by exposure to alcohol-related cues were not affected by negative or distressed moods.

In a study conducted by Ray (2011), the results showed that in both mood groups, alcohol cues increased the urge to consume alcohol. In contrast to our hypothesis, alcohol cues produced greater increases in the urge to drink in the neutral mood condition than in the stressed mood condition.

Finally, in the study by Pratt and Davidson (2009), there were no significant differences in craving between the stress and neutral mood condition. This indicates that stress did not lead to increased cue sensitivity, in contrast to our hypothesis. However, the authors of the study suggested that this finding may have been caused by a ceiling effect, since craving rates in all conditions were relatively high. Alternatively, craving was measured after alcohol consumption, which we believe may have had an attenuating effect on craving. 
Snelleman, M., Schoenmakers, T.M., Mheen, D. van de. The relationship between perceived stress and cue sensitivity for alcohol. Addictive Behaviors: 2014, 39(12), 1884-1889

In sum, two studies in category one provided evidence that supported our hypothesis that stress affects cue sensitivity (Coffey et al., 2006 and Nosen et al., 2012), whereas the remaining three studies did not (Jansma et al., 2000, Pratt and Davidson, 2009 and Ray, 2011).

\subsection{Category 2}

All studies in the second category $(\mathrm{N}=3)$ used stressful tasks (i.e., giving an oral presentation that would be evaluated, a public speaking task with verbal interaction) to induce stress in addition to either in vivo presentation of alcohol-related cues including physiological and subjective measurements of cue sensitivity (Nesic \& Duka, 2006), or an attentional bias task that exposed participants to alcohol-related pictures (Field and Powell, 2007 and Field and Quigley, 2009).

Two separate studies were almost identical in the type of sample selected, study design and recorded measures. In both studies, an attentional bias for alcohol-related pictures was observed only after exposure to the stressor, but not after neutral mood induction. However, this effect was found only in the group of heavy social drinkers whose primary drinking motive was 'drinking to cope'. Thus, these studies support our hypothesis, but only in a subset of drinkers.

In the third study (Nesic \& Duka, 2006) both groups exhibited increased skin conductance during cue exposure and increases in craving after cue exposure, indicating overall cue sensitivity. However, no differences were found in craving between the stress and neutral condition. Effects of stress on skin conductance differed between male and female participants: in males, no differences were found between the stress and the neutral condition, whereas in females, skin conductance increased during alcohol cue exposure only in the neutral condition. Thus, this study did not support our hypothesis.

Of the three studies of this category, all of which included heavy social drinkers, two supported our hypothesis. The two supporting studies (Field and Powell, 2007 and Field and Quigley, 2009) however, reported effects in coping drinkers only.

\subsection{Category 3}

In the correlational studies of the third category $(\mathrm{N}=2$, reported in four articles), all participants were exposed to a stress induction, but there was no neutral mood induction. Stress was induced by looking at aversive pictures (exposure to emotioneliciting material) and cues consisted of alcohol-related pictures. Cue sensitivity was assessed by measuring changes between subjective pre-stress induction and post-cue exposure craving (Garland, 2011, Garland, Carter, Ropes and Howard, 2012 and Garland, Franken, Sheetz and Howard, 2012) or using an attentional bias task (Garland et al., 2010).

In the first study, which was cited in three articles (Garland, 2011, Garland, Carter, Ropes and Howard, 2012 and Garland, Franken, Sheetz and Howard, 2012), the results demonstrated an increase in self-reported stress from pre-stress induction (i.e. before stress induction and cue exposure) to post-exposure (i.e. after cue exposure) and a simultaneous increase in craving. Both stress and craving were measured before stress induction and after cue exposure but not in between. Therefore, these results provide correlational evidence supporting our hypothesis: there is evidence that increased stress is associated with increases in craving after cue exposure in alcohol-dependent patients. 
Snelleman, M., Schoenmakers, T.M., Mheen, D. van de. The relationship between perceived stress and cue sensitivity for alcohol. Addictive Behaviors: 2014, 39(12), 1884-1889

The second study (Garland et al., 2010) was selected because of an embedded stress induction and cue exposure paradigm. The paradigm was used before and after treatment (10-week interval). In this study, reduced levels of stress after mindfulness training co-occurred with reduced attentional bias. This study indicates that stress levels may affect sensitivity to alcohol-related cues.

Three of the four articles describe the results of a single study (Garland, 2011, Garland, Carter, Ropes and Howard, 2012 and Garland, Franken, Sheetz and Howard, 2012) and all articles in this category provide correlational evidence supporting our hypothesis. Because of the nature of correlational designs, we cannot draw conclusions about the causal relationship between stress and cue sensitivity. We can infer, however, that changes in stress levels and cue sensitivity measures are associated.

\section{DISCUSSION}

In the present review, we examined evidence supporting the relationship between stress and cue sensitivity. Overall, we conclude that the relationship between stress and cue sensitivity seems to exist; however, it is complex. Mixed results were reported in the review studies. We observed that stress increased cue reactivity in 6 of 10 studies (reported in 12 articles). Our hypothesis was supported mostly by experimental between-subjects studies (category $2 ; \mathrm{N}=2$ ) and correlational studies (category $3 ; \mathrm{N}=4$ ) with medium to large effect sizes. However, it should be noted that these designs are considered to be weaker than experimental within-subjects studies (category 1) in their ability to infer causal relationships. Of the studies using within-subjects designs, three did not support our hypothesis whereas two (one of medium effect size, one large) did support it. It is noteworthy that the two supporting studies from category 1 sampled patients with comorbid PTSD and that the two supporting studies from category 2 found effects in coping drinkers only. Thus the four experimental studies that supported our hypothesis all studied specific groups of participants.

Considering the positive findings reported by within-subjects and between-subjects studies, it appears that stress-induced cue sensitivity exists in coping drinkers and alcohol-dependent patients with PTSD. Individuals of the latter group are likely to comprise mostly coping drinkers as well. Often, people with PTSD may become dependent on alcohol because of its rewarding properties to reduce stress and negative affect (Dixon et al., 2009, Stewart et al., 2004 and Ullman et al., 2006). Thus, these people can be viewed as drinking to cope with negative affect. Therefore coping drinking seems to be a moderating factor in the relationship between stress and cue sensitivity.

Using the present review as a basis, it appears that stress induced via exposure to emotion-eliciting material, i.e., psychological stress, led to increased cue sensitivity, while stress induced via cognitive tasks, i.e., physical and psychological stress did not. This finding may be explained in light of the Affective Processing Model of Negative Reinforcement (Baker et al., 2004) as referred to in the introduction. Exposure to emotion-eliciting material evokes more negative affect as compared to cognitive induction tasks, the latter evoking more physical stress and arousal. Therefore, it could be that the exposure to emotion-eliciting material evokes negative affective states comparable to those that were alleviated by drinking in the past (i.e. drinking to cope; Cooper, 1994). As a conditioned effect, when confronted with this 
Snelleman, M., Schoenmakers, T.M., Mheen, D. van de. The relationship between perceived stress and cue sensitivity for alcohol. Addictive Behaviors: 2014, 39(12), 1884-1889

type of affect one is motivated to alleviate this by drinking, which enhances the rewarding properties of alcohol cues and thus cue sensitivity.

On the other hand, cognitive tasks evoke more physical stress and an acute arousal state. These states may be evoked less often in daily life. Furthermore, because of their more transient nature they have less likely been alleviated by drinking as a coping mechanism. Therefore, we believe that the conditioned effect that occurs in coping drinkers after psychological stress is unlikely to occur to the same extent after acute physical stress. In general, these acute stress states thus have no significant link with past drinking and therefore do not enhance cue sensitivity.

In future research, the type of stress of interest should be considered. Based on the above, we would suggest that evoking negative states that have been paired with drinking in the past is more important in alcohol cue sensitivity than acute arousal states that are less frequent in daily life and were not often accompanied by drinking. To examine the effect of physical and psychological stress on cue sensitivity, three types of measures should then be incorporated: self-report measures, physiological measures and attentional bias measures. In this review, we reviewed studies using one or two of these types of measures, but not a single study used all three types of measures. In addition, the role of coping drinking should be examined in detail, to investigate whether coping drinking plays a role in the relationship between stress and cue sensitivity.

Since there are not many studies yet with a strong study design, there is a clear need for replication, rendering our conclusions tentative. There may be different factors at play. Our review points toward (1) differences between the effect of psychological stress and physiological stress on cue-sensitivity, and (2) individual differences regarding coping drinking which may explain stress-induced cues sensitivity. We conclude that the relationship between stress and sensitivity to alcohol cues appears to exist, most noticeably in people who drink to cope with negative affect.

\section{Role of funding source}

Nothing declared.

\section{Contributors}

Prof. dr. van de Mheen reviewed and commented the protocol and the manuscript.

Dr. Schoenmakers has written the protocol, assisted with the literature selection, and reviewed the manuscript. Ms. Snelleman carried out the literature search and selection, analyzed the data and has written the manuscript.

All authors contributed to and have approved the final manuscript.

\section{Conflict of interest}

All authors declare that they have no conflicts of interest.

\section{REFERENCES}

Baker et al., 2004

T.B. Baker, M.E. Piper, D.E. McCarthy, M.R. Majeskie, M.C. Fiore

Addiction motivation reformulated: An affective processing model of negative reinforcement

Psychological Review, 111 (1) (2004), pp. 33-51

http://dx.doi.org.ezproxy.library.wur.nl/10.1037/0033-295X.111.1.33

Bohn et al., 1995

M.J. Bohn, D.D. Krahn, B.A. Staehler

Development and initial validation of a measure of drinking urges in abstinent alcoholics Alcoholism, Clinical and Experimental Research, 19 (3) (1995), pp. 600-606

Boothby and Doering, 2005 
Snelleman, M., Schoenmakers, T.M., Mheen, D. van de. The relationship between perceived stress and cue sensitivity for alcohol. Addictive Behaviors: 2014, 39(12), 1884-1889

L.a. Boothby, P.L. Doering

Acamprosate for the treatment of alcohol dependence

Clinical Therapeutics, 27 (6) (2005), pp. 695-714

http://dx.doi.org.ezproxy.library.wur.nl/10.1016/j.clinthera.2005.06.015

Carter and Tiffany, 1999

B.L. Carter, S.T. Tiffany

Meta-analysis of cue-reactivity in addiction research

Addiction, 94 (3) (1999), pp. 327-340 http://dx.doi.org.ezproxy.library.wur.nl/10.1046/j.13600443.1999.9433273.x

Coffey et al., 2006

S.F. Coffey, P.R. Stasiewicz, P.M. Hughes, M.L. Brimo

Trauma-focused imaginal exposure for individuals with comorbid posttraumatic stress disorder and alcohol dependence: Revealing mechanisms of alcohol craving in a cue reactivity paradigm

Psychology of Addictive Behaviors: Journal of the Society of Psychologists in Addictive Behaviors, 20 (4) (2006), pp. 425-435

http://dx.doi.org.ezproxy.library.wur.nl/10.1037/0893-164X.20.4.425

Cooney et al., 1997

N.L. Cooney, M.D. Litt, P.a Morse, L.O. Bauer, L. Gaupp

Alcohol cue reactivity, negative-mood reactivity, and relapse in treated alcoholic men

Journal of Abnormal Psychology, 106 (2) (1997), pp. 243-250

http://dx.doi.org.ezproxy.library.wur.nl/10.1037/0021-843X.106.2.243

Cooper, 1994

M.L. Cooper

Motivations for alcohol use among adolescents: Development and validation of a four-factor model

Psychological Assessment, 6 (2) (1994), pp. 117-128

http://dx.doi.org.ezproxy.library.wur.nl/10.1037/1040-3590.6.2.117

Dickerson and Kemeny, 2004

S.S. Dickerson, M.E. Kemeny

Acute stressors and cortisol responses: A theoretical integration and synthesis of laboratory research

Psychological Bulletin, 130 (3) (2004), pp. 355-391

http://dx.doi.org.ezproxy.library.wur.nl/10.1037/0033-2909.130.3.355

Dixon et al., 2009

L.J. Dixon, E.W. Leen-Feldner, L.S. Ham, M.T. Feldner, S.F. Lewis

Alcohol use motives among traumatic event-exposed, treatment-seeking adolescents: Associations with posttraumatic stress

Addictive Behaviors, 34 (12) (2009), pp. 1065-1068

http://dx.doi.org.ezproxy.library.wur.nl/10.1016/j.addbeh.2009.06.008

Field and Cox, 2008

M. Field, W.M. Cox

Attentional bias in addictive behaviors: A review of its development, causes, and consequences

Drug and Alcohol Dependence, 97 (1-2) (2008), pp. 1-20

http://dx.doi.org.ezproxy.library.wur.nl/10.1016/j.drugalcdep.2008.03.030

Field and Powell, 2007

M. Field, H. Powell

Stress increases attentional bias for alcohol cues in social drinkers who drink to cope

Alcohol and Alcoholism (Oxford, Oxfordshire), 42 (6) (2007), pp. 560-566

http://dx.doi.org.ezproxy.library.wur.nl/10.1093/alcalc/agm064

Field and Quigley, 2009

M. Field, M. Quigley

Mild stress increases attentional bias in social drinkers who drink to cope: A replication and extension

Experimental and Clinical Psychopharmacology, 17 (5) (2009), pp. 312-319

http://dx.doi.org.ezproxy.library.wur.nl/10.1037/a0017090

Finney et al., 1996 
Snelleman, M., Schoenmakers, T.M., Mheen, D. van de. The relationship between perceived stress and cue sensitivity for alcohol. Addictive Behaviors: 2014, 39(12), 1884-1889

J.W. Finney, A.C. Hahn, R.H. Moos

The effectiveness of inpatient and outpatient treatment for alcohol abuse: The need to focus on mediators and moderators of setting effects

Addiction, 91 (12) (1996), pp. 1773-1796

http://dx.doi.org.ezproxy.library.wur.nl/10.1046/j.1360-0443.1996.911217733.x

Garland, 2011

E.L. Garland

Trait mindfulness predicts attentional and autonomic regulation of alcohol cue-reactivity

Journal of Psychophysiology, 25 (4) (2011), pp. 180-189

http://dx.doi.org.ezproxy.library.wur.nl/10.1027/0269-8803/a000060

Garland, Carter, Ropes and Howard, 2012

E.L. Garland, K. Carter, K. Ropes, M.O. Howard

Thought suppression, impaired regulation of urges, and Addiction-Stroop predict affectmodulated cue-reactivity among alcohol dependent adults

Biological Psychology, 89 (1) (2012), pp. 87-93

http://dx.doi.org.ezproxy.library.wur.nl/10.1016/j.biopsycho.2011.09.010

Garland, Franken, Sheetz and Howard, 2012

E.L. Garland, I.H.a Franken, J.J. Sheetz, M.O. Howard

Alcohol attentional bias is associated with autonomic indices of stress-primed alcohol cuereactivity in alcohol-dependent patients

Experimental and Clinical Psychopharmacology, 20 (3) (2012), pp. 225-235

http://dx.doi.org.ezproxy.library.wur.nl/10.1037/a0027199

Garland et al., 2010

E.L. Garland, S.A. Gaylord, C.A. Boettiger, M.O. Howard

Mindfulness training modifies cognitive, affective, and physiological mechanisms implicated in alcohol dependence: Results of a randomized controlled pilot trial

Journal of Psychoactive Drugs, 42 (2) (2010), pp. 177-192

http://dx.doi.org.ezproxy.library.wur.nl/10.1080/02791072.2010.10400690

Grüsser et al., 2004

S.M. Grüsser, J. Wrase, S. Klein, D. Hermans, M.N. Smolka, M. Ruf, et al.

Cue-induced activation of the striatum and medial prefrontal cortex is associated with subsequent relapse in abstinent alcoholics

Psychopharmacology, 175 (3) (2004), pp. 296-302

http://dx.doi.org.ezproxy.library.wur.nl/10.1007/s00213-004-1828-4

Jansma et al., 2000

A. Jansma, M.H.M. Breteler, G.M. Schippers, C.A. De Jong, C.P. Van Der Staak

No effect of negative mood on the alcohol cue reactivity of in-patient alcoholics

Addictive Behaviors, 25 (4) (2000), pp. 619-624

http://dx.doi.org.ezproxy.library.wur.nl/10.1016/S0306-4603(99)00037-4

Koob and Le Moal, 2001

G.F. Koob, M. Le Moal

Drug addiction, dysregulation of reward, and allostasis

Neuropsychopharmacology: Official Publication of the American College of

Neuropsychopharmacology, 24 (2) (2001), pp. 97-129

http://dx.doi.org.ezproxy.library.wur.nl/10.1016/S0893-133X(00)00195-0

Nesic and Duka, 2006

J. Nesic, T. Duka

Gender specific effects of a mild stressor on alcohol cue reactivity in heavy social drinkers

Pharmacology, Biochemistry, and Behavior, 83 (2) (2006), pp. 239-248

http://dx.doi.org.ezproxy.library.wur.nl/10.1016/j.pbb.2006.02.006

Nosen et al., 2012

E. Nosen, Y.I. Nillni, E.C. Berenz, J.a Schumacher, P.R. Stasiewicz, S.F. Coffey

Cue-elicited affect and craving: Advancement of the conceptualization of craving in cooccurring posttraumatic stress disorder and alcohol dependence

Behavior Modification, 36 (6) (2012), pp. 808-833

http://dx.doi.org.ezproxy.library.wur.nl/10.1177/0145445512446741

Pratt and Davidson, 2009

W.M. Pratt, D. Davidson 
Snelleman, M., Schoenmakers, T.M., Mheen, D. van de. The relationship between perceived stress and cue sensitivity for alcohol. Addictive Behaviors: 2014, 39(12), 1884-1889

Role of the HPA axis and the A118G polymorphism of the mu-opioid receptor in stressinduced drinking behavior

Alcohol and Alcoholism, 44 (4) (2009), pp. 358-365 http://dx.doi.org.ezproxy.library.wur.nl/10.1093/alcalc/agp007

Ray, 2011

L.A. Ray

Stress-induced and cue-induced craving for alcohol in heavy drinkers: Preliminary evidence of genetic moderation by the OPRM1 and $\mathrm{CRH}$-BP genes

Alcoholism, Clinical and Experimental Research, 35 (1) (2011), pp. 166-174 http://dx.doi.org.ezproxy.library.wur.nl/10.1111/j.1530-0277.2010.01333.x

Robinson and Berridge, 1993

T.E. Robinson, K.C. Berridge

The neural basis of drug craving: an incentive-sensitization theory of addiction

Brain Research. Brain Research Reviews, 18 (3) (1993), pp. 247-291

Robinson and Berridge, 2001

T.E. Robinson, K.C. Berridge

Incentive-sensitization and addiction

Addiction, 96 (1) (2001), pp. 103-114

http://dx.doi.org.ezproxy.library.wur.nl/10.1080/09652140020016996

Schulze and Jones, 2000

D. Schulze, B.T. Jones

Desire for alcohol and outcome expectancies as measures of alcohol cue-reactivity in social drinkers

Addiction, 95 (7) (2000), pp. 1015-1020

Stewart et al., 2004

S.H. Stewart, T.L. Mitchell, K.D. Wright, P. Loba

The relations of PTSD symptoms to alcohol use and coping drinking in volunteers who responded to the Swissair Flight 111 airline disaster

Journal of Anxiety Disorders, 18 (1) (2004), pp. 51-68

http://dx.doi.org.ezproxy.library.wur.nl/10.1016/j.janxdis.2003.07.006

Tapert et al., 2003

S.F. Tapert, E.H. Cheung, G.G. Brown, L.R. Frank, M.P. Paulus, A.D. Schweinsburg, et al. Neural response to alcohol stimuli in adolescents with alcohol use disorder

Archives of General Psychiatry, 60 (7) (2003), pp. 727-735

http://dx.doi.org.ezproxy.library.wur.nl/10.1001/archpsyc.60.7.727

Ullman et al., 2006

S.E. Ullman, H.H. Filipas, S.M. Townsend, L.L. Starzynski

Correlates of comorbid PTSD and drinking problems among sexual assault survivors

Addictive Behaviors, 31 (1) (2006), pp. 128-132

http://dx.doi.org.ezproxy.library.wur.nl/10.1016/j.addbeh.2005.04.002

Waters et al., 2009

A.J. Waters, B.L. Carter, J.D. Robinson, D.W. Wetter, C.Y. Lam, W. Kerst, et al.

Attentional bias is associated with incentive-related physiological and subjective measures

Experimental and Clinical Psychopharmacology, 17 (4) (2009), pp. 247-257

http://dx.doi.org.ezproxy.library.wur.nl/10.1037/a0016658 


\section{TABLES AND FIGURES}
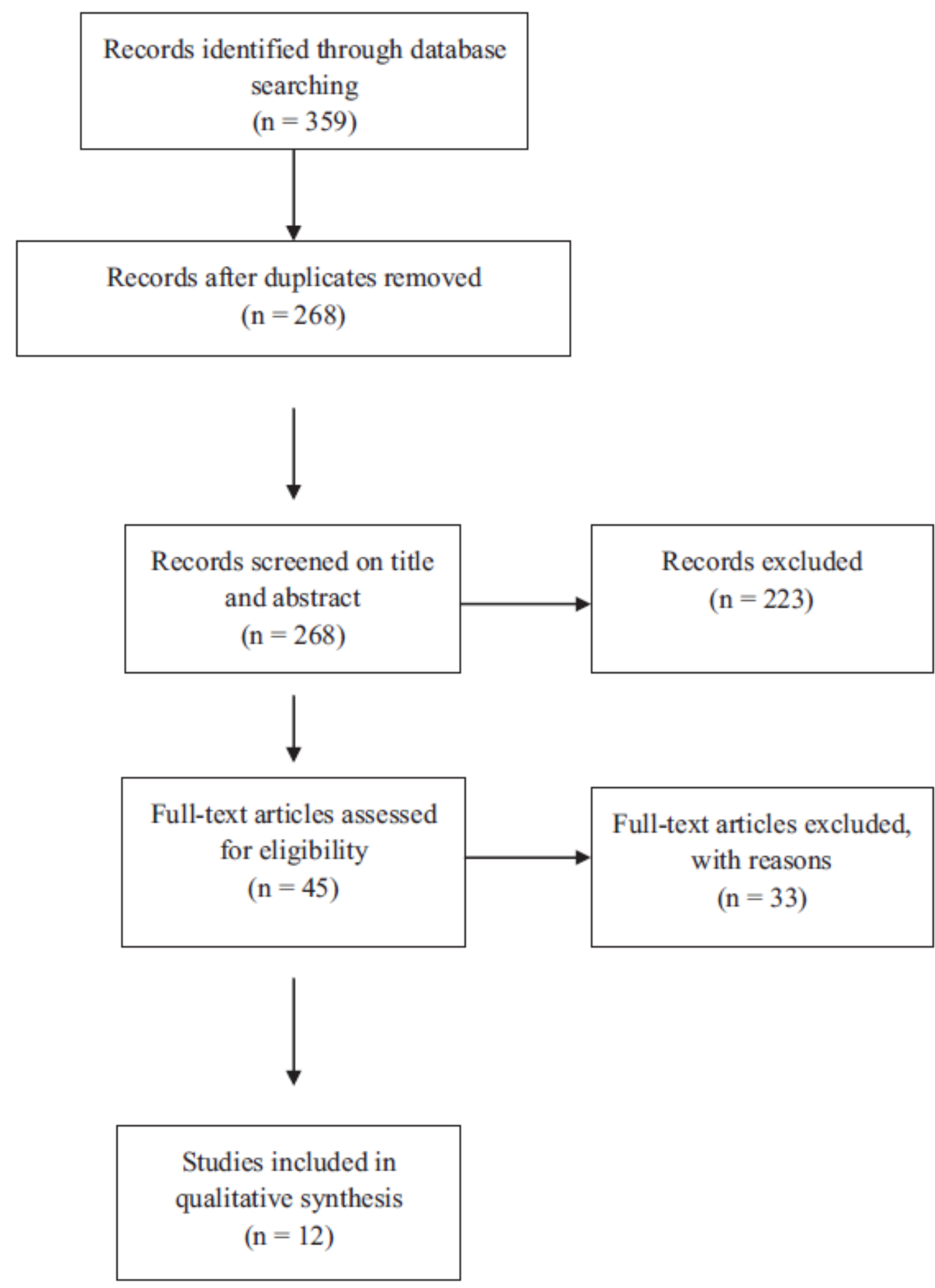

Fig. 1. Search strategy and selection process of articles in review. 
Table 1

Summary of selected artides for the effect of stress on cue sensitivity.

\begin{tabular}{|c|c|c|c|c|c|}
\hline Study & Sample & Type of mood induction & Type of cue exposure & Study design & Results on effect of stress on cue sensitivity \\
\hline $\begin{array}{l}\text { Coffey, Stasiewiz, Hughes, and } \\
\text { Brimo (2006) }\end{array}$ & $\begin{array}{l}43 \text { outpatients with comorbid AD } \\
\text { and PTSD }\end{array}$ & $\begin{array}{l}\text { Personalized trauma imagery script vs. } \\
\text { neutral script }\end{array}$ & $\begin{array}{l}\text { Sight and smell of } \\
\text { participant's preferned } \\
\text { alcohdic beverag: vs. bottled } \\
\text { spring water }\end{array}$ & $\begin{array}{l}\text { Within-subject design. CS measures: } \\
\text { craving }\end{array}$ & $\begin{array}{l}\text { Craving increased when confronted with trauma and } \\
\text { alcohol cues compared to neutral mood and akohol cue } \\
\text { combination (Cohen's } d=0.86 \text { ) }\end{array}$ \\
\hline Field and Powell (2007) & $\begin{array}{l}44 \text { heavy social drinking students } \\
\text { ( } 19 \text { low CM, } 25 \text { high CM) }\end{array}$ & $\begin{array}{l}\text { Expectation of giving a speech and } \\
\text { being evaluated vs, solving simple } \\
\text { anagrams }\end{array}$ & $\begin{array}{l}\text { Alcohol-related vs, neutral } \\
\text { pictures during a visual } \\
\text { probe task }\end{array}$ & $\begin{array}{l}\text { Between-subject design. CS measure, } \\
\text { attentional bias for alcohol-related pictures }\end{array}$ & $\begin{array}{l}\text { in high } \mathrm{CM} \text { drinkers only, stress induction led to an } \\
\text { increase in attentional bias for alcohol-related cues } \\
\text { (Cohen's } d=1.40 \text { ), as compared to neutral mood in- } \\
\text { duction (Cohen's } d=0.18 \text { ) }\end{array}$ \\
\hline Field and Quigley (2009) & $\begin{array}{l}58 \text { heavy so cial drinking students } \\
\text { (28 low CM; } 30 \text { high CM) }\end{array}$ & $\begin{array}{l}\text { Expectation of giving a speech and } \\
\text { being evaluated vs. solving simple } \\
\text { anagrams }\end{array}$ & $\begin{array}{l}\text { Alcohol-related vs, neutral } \\
\text { pictures during a visual } \\
\text { probe task }\end{array}$ & $\begin{array}{l}\text { Between-subject design. CS measure, } \\
\text { attentional bias for alcohol-related pictures }\end{array}$ & $\begin{array}{l}\text { In high CM drinkers only, stress induction led to an } \\
\text { increase in attentional bias for alcohol-related cues as } \\
\text { compared to neutral mood induction for both atten- } \\
\text { tional engagement (Cohen's } d=1.39 \text { ) and attention- } \\
\text { al maintenance (Cohen's } d=0.64 \text { ) }\end{array}$ \\
\hline $\begin{array}{l}\text { Garland (2011), Garland, Carter, } \\
\text { Ropes, and Howard (2012), } \\
\text { Garland, Franken, Sheetz and } \\
\text { Howard (2012) }\end{array}$ & $\begin{array}{l}58 \text { abstinent alcohol-dependent } \\
\text { patients, in treatment }\end{array}$ & Looking at aversive pictures & $\begin{array}{l}\text { Looking at alcohol-related } \\
\text { pictures }\end{array}$ & $\begin{array}{l}\text { Correlational design } C S \text { measure; change in } \\
\text { craving pre- to posttest }\end{array}$ & $\begin{array}{l}\text { There was a significant correlation between change in } \\
\text { stress and change in craving, when comparing baseline } \\
\text { and post-alcohol cue exposure (Pearson's } r=0.57 \text { ) }\end{array}$ \\
\hline $\begin{array}{l}\text { Garland, Gaylord, Boettiger, and } \\
\text { Howard (2010) }\end{array}$ & $\begin{array}{l}53 \text { abstinent alcohol-dependent } \\
\text { patients in treatment }\end{array}$ & Looking at aversive pictures & $\begin{array}{l}\text { Looking at alcohol-related } \\
\text { pictures }\end{array}$ & $\begin{array}{l}\text { Between-subject design, with correlational } \\
\text { outcome. Mindfulness therapy vs, standard } \\
\text { support group therapy (random allocation), } \\
\text { CS measure: dot-probe task both pre and } \\
\text { post treatment }\end{array}$ & $\begin{array}{l}\text { A reduction of stress after } 10 \text { weeks of mindfulness } \\
\text { (Cohen's } d=0.74 \text { ) accompanied a reduced altentional } \\
\text { bias for alcohol-related cues (Cohen's } d=1.03 \text { ). }\end{array}$ \\
\hline $\begin{array}{l}\text { Jansma, Breteler, Schippers, De Jong. } \\
\text { and Van Der Staak (2000) }\end{array}$ & 40 abstinent inpatient alcoholics & $\begin{array}{l}\text { All participants: neutral mood induction: } \\
\text { reading a fmily magazine } \\
\text { Half of participants distressed induction: } \\
\text { performing a high speed complicated } \\
\text { task while receiving negative feedback } \\
\text { Other half: depressing mood by listening } \\
\text { to depressing mood with the instruction } \\
\text { to get sad }\end{array}$ & $\begin{array}{l}\text { Pouring a glass from a bottle } \\
\text { of alcohol and sniff the glass } \\
\text { five consecutive times. No } \\
\text { neutral cue }\end{array}$ & $\begin{array}{l}\text { Combined within and between-subject design. } \\
\text { CS measures: desire to drink, blood pressure, } \\
\text { and heart rate variability }\end{array}$ & $\begin{array}{l}\text { Alcohol cue sensitivity was found, but not dependent on } \\
\text { mood. Cue sensitivity was not higher when distressed } \\
\text { or depressed as compared to a neutral mood for all } \\
\text { measures: } \\
\text { Desire to drink: Cohen's } d=0.15 \\
\text { Heart rate variability: Cohen's } d=0.00 \\
\text { Blood pressure: Cohen's } d=0.11\end{array}$ \\
\hline Nesic and Duka (2006) & 32 heavy social drinking students & $\begin{array}{l}\text { Prepare and deliver a 5-min speech } \\
\text { followed by a mental arithmetic task. } \\
\text { Control condition: booking at an art } \\
\text { history book, assessing paintings and } \\
\text { completing dot-to-dot pictures }\end{array}$ & $\begin{array}{l}\text { Hold ing and smelling the } \\
\text { participant's preferred } \\
\text { alco holic beverage }\end{array}$ & $\begin{array}{l}\text { Between-subjects design. CS measures: skin } \\
\text { conductance and desire for alcohol, measured } \\
\text { after stress manipulation and after alcohol cue } \\
\text { exposure }\end{array}$ & $\begin{array}{l}\text { Overall effects of cue exposure were found for mild } \\
\text { desire (Cohen's } d=1.16 \text { ) and strong desire (Cohen's } \\
d=1.28 \text { ). however, there was no difference in desire } \\
\text { for alcohol after cue exposure between the stress and } \\
\text { control condition (Cohen's } d=0.39 \text { ). } \\
\text { Skin conductance increased in non-stressed females } \\
\text { (Cohen's } d=2.01 \text { ), but not in stressed males } \\
\text { (Cohen's } d=0.37 \text { ), and females (Cohen's } d=0.73 \text { ), } \\
\text { and in non-stressed males (Cohen's } d=1.97 \text { ) }\end{array}$ \\
\hline Nosen et al (2012) & $\begin{array}{l}108 \text { treatment-seeking adults with } \\
\text { comorbid PTSD and alcohol } \\
\text { dependence }\end{array}$ & $\begin{array}{l}\text { Trauma imagery (narrative description } \\
\text { of person's worst traumatic event) vs. } \\
\text { neutral imagery (narrative about } \\
\text { changing a light bulb) }\end{array}$ & $\begin{array}{l}\text { Alcohol cue was the } \\
\text { participant's preferred } \\
\text { beverage. Neutral cue was } \\
\text { a bottle of water }\end{array}$ & $\begin{array}{l}\text { Within-subjects design CS measures: positive } \\
\text { and negative affect, and alcohol craving Nl } \\
\text { participants underwent four countertal anced } \\
\text { imagery-cue combinations neutral-neutral } \\
\text { (NN), trauma-neutral (TN), neutral-al cohol } \\
\text { (NA) and trauma-alcohol (TA) }\end{array}$ & $\begin{array}{l}\text { There was a significant differener in alcohol craving after } \\
\text { trauma imaggry followed by alcohol cues as compared to } \\
\text { neutral mood followed by alcohol cues (Cohen's } d=041 \text { ) }\end{array}$ \\
\hline Pratt and Davidson (2009) & $\begin{array}{l}74 \text { non-treatment seeking alcohol- } \\
\text { dependent adults whose preferred } \\
\text { beverage was beer }\end{array}$ & $\begin{array}{l}\text { Stress was induced using the Paced } \\
\text { Auditorial Serial Addition Test } \\
\text { (PASAT). Neutral condition was sitting } \\
\text { quietly for the same length of time as } \\
\text { the PASAT }\end{array}$ & $\begin{array}{l}\text { Neutral cue was water. } \\
\text { Akcohol cue was preferred } \\
\text { beer brand in a glass behind a } \\
\text { sliding door, when accessible, } \\
\text { one could drink the beer }\end{array}$ & $\begin{array}{l}\text { Within-subject design. CS measure was } \\
\text { craving }\end{array}$ & $\begin{array}{l}\text { There were no significant differences in alco hol craving } \\
\text { between stress and neutral condition aftercue exposure } \\
\text { (Cohen's } d=0.108 \text { ) }\end{array}$ \\
\hline Ray (2011) & $\begin{array}{l}64 \text { non-treatment seeking heavy } \\
\text { drinkers }\end{array}$ & $\begin{array}{l}\text { Stress imagery of stressful recent } \\
\text { personal events; neutral imagery of } \\
\text { recent neutral personal events }\end{array}$ & $\begin{array}{l}\text { Exposure to water and } \\
\text { alcohol beverages }\end{array}$ & $\begin{array}{l}\text { Within-subject design. CS measure was } \\
\text { craving }\end{array}$ & $\begin{array}{l}\text { Presentation of al cohol cues increased akcohol craving and } \\
\text { nesat ive mood across both stress and neutral imagery. } \\
\text { Alcohol cues produced greater increases inc caving after } \\
\text { neutral imagery when compared to stress imagery } \\
\text { (Cohen's } s=1.83 \text { ) }\end{array}$ \\
\hline
\end{tabular}

